\title{
Effect of Lumbar Hyperlordosis Correction on Craniovertebral Angle in Low Back Pain Patients
}

\author{
FATMA ALZAHRAA M. ALI, M.Sc.; AWATEF M. LABIB, Ph.D.; MAGDA G. SEDHOM, Ph.D. and \\ SHIMAA T. ABU EL-KASEM, Ph.D.
}

The Department of Basic Science, Faculty of Physical Therapy, Cairo University

\begin{abstract}
Background: Several studies have indicated the clinical and functional importance of lumbar lordosis. It is a key component in maintaining the sagittal balance.

Aim of Study: To investigate the effect of lumbar hyperlordosis correction on crainovertebral angle in chronic low back pain patients.

Subjects and Methods: 30 patients of both genders diagnosed as chronic low back pain with lumbar hyperlordosis (cobb anlge $>40$ degrees) selected from outpatient clinic of the faculty of physical therapy, Beni Suef University through the period between October 2019 to January 2020. Their ages ranged from 20 to 35 years. Patients were assigned randomly by sealed envelope into two groups after signing institutionally approved consent. Group A (Experimental group): 15 patients received muscle energy technique (MET) for 3 sessions/week for 4 weeks. Group B (Control group): 15 patients received William program for 3 sessions/week for 4 week. Lumbar lordosis angle was measured by plain X-ray imaging, craniovertebral angle by photographic analysis method, pain intensity level by visual analogue scale, trunk range of motion by tape (flexion, extension, side bending and rotation) before and after four weeks of treatment.
\end{abstract}

Results: The study findings revealed that there was a significant improvement in the craniovertebral angle of both groups post treatment compared with that pre treatment $(p=$ 0.0001 ), There was significant increase in trunk range of motion in both groups post treatment compared with that pre treatment $(p=0.0001)$, There was a significant decrease in pain intensity on VAS in the both groups post treatment compared with that pre treatment $(p=0.0001)$.

Conclusion: The correction of lumbar hyperlordosis had a positive effect on improving craniovertebral angle, improving trunk range of motion, and decrease pain level in chronic low back pain patients.

Key Words: Lumbar hyperlordosis - Craniovertebral angle - Low back pain.

Correspondence to: Dr. Fatma Alzahraa M. Ali, The Department of Basic Science, Faculty of Physical Therapy, Cairo University

\section{Introduction}

THE vertebral column is the main axis in the human body and plays an important role in maintaining an upright posture [1]. Spinal curvature in the sagittal plane, especially lumbar lordosis, is necessary for effective weight bearing, increasing efficiency of paraspinal muscles, and maintaining erect posture [2]. Lumbar lordosis is the ventral curvature of the spine formed by wedging of the lumbar vertebrae and intervertebral discs [3]. It is defined as the angle between L1-S1 [4].

Abnormal curvature of the spine can create increased stress on the body which can, overtime, lead to muscle imbalance. One of the most important postural deformities of the spinal column is lumbar hyperlordosis which means exaggerated curve of lumbar spine [5]. According to previous studies, the normal lordosis angle is $30^{\circ}$ and angles $>40^{\circ}$ are considered as hyperlordosis [5].

The lumbosacral region is the most important region in the vertebral column in terms of mobility and weight bearing. Mechanical disorders of this region cause LBP [6].Various studies have examined the relationship between changes in the angle of the lumbar spine and back pain [7].

Among the causes of LBP, the alteration of lumbar curvature on sagittal plane mostly due to aberration of posture plays a great role on LBP [8]. The restoration of lumbar lordosis is important in the restoration of the balance in the sagittal plane of the spine [9].

All the segments in the axial skeleton and lower limbs function as parts of a closed chain; movement at one joint will create movement in at least one other linkage in the chain [10]. Cervical posture in either standing or sitting position is believed to be 
dependent on the way the trunk, pelvis, arms and legs are positioned [11].

Postural chain refers to the position of a joint that is related to another joint when a body is correctly postured. Postural chains affect motions and positions because of structural and functional mechanisms. That is, a spine from the cervical vertebra to coccyx is connected organically with each other so that changes in one region can affect the activities of the other regions. Therefore, bad posture in one region can affect the overall spine from head to pelvis [12]. The human body is thought to be connected structurally so that changes in one region affect postures of adjacent regions [13]. There is a gap in literature review regarding effect of lumbar hyperlordosis correction on cervical spine posture. Therefore, this study was designed to investigate whether lumbar hyperlordosis correction is associated with changes in craniovertebral angle which would help in predicting and preventing degenerative changes in cervical spine.

\section{Subjects and Methods}

Thirty patients of both genders were selected (age: 20 to 35) years, they were selected from the outpatient clinic of the faculty of physical therapy, Beni Suef University through the period between October 2019 to January 2020. They were diagnosed as chronic low back pain with lumbar hyperlordosis (cobb angle >40). Patients were assigned randomly by sealed envelope into two groups. Group A (Experimental group): 15 patients (8 females and 7 males) received muscle energy technique (MET) for 3 sessions/week for 4 weeks. Group B (Control group): 15 patients (7 females and 8 males) received William program for 3 sessions/week for 4 weeks. All patients were given full explanation of the study procedures, and signed informed consents were obtained before participation. This study was approved by the Ethics Committee for Scientific Research of the Faculty of Physical Therapy, Cairo University. The history of subjects was taken to exclude Bone disease, Disc lesion, osteophytes, Spondylolithesis, Any sensory problems or disturbance, any underlying disease such as malignancy, infection or systemic disease of the musculoskeletal system, and previous vertebral fractures or major spinal structural abnormality.

Sample size calculation was based on the data from pilot study performed prior to the actual study using G*POWER statistical software (version 3.1.9.2; Franz Faul, Universitat Kiel, Germany) [F tests-MANOVA: Repeated measures, within- between interaction, $\alpha=0.05, \beta=0.2$, and large effect size] and revealed that the appropriate sample size for this study was $\mathrm{N}=30$.

\section{Methods:}

\section{1-Plain X-ray imaging was used to measure lumbar lordosis angle:}

Standard lateral lumbar radiographs (PHILIPS, Germany, January, 1998) were obtained with patients in standing position with arms folded on the chest placing the hands in the clavicular fossae [14].

\section{2- Photographic posture analysis method was used to measure craniovertebral angle:}

\section{This method consisted of:}

A camera (16 mega pixel), A plastic pointer markers, Computer for downloading images, Windows 8 , and Surgimap software.

Volunteers were asked to stand in their comfortable posture in front of a plain and white wall looking forward, volunteers were then instructed to visually focus on a point on the wall directly in front of them hanging their hands at their sides. The base of the camera was set at the height of the subjects' shoulder. A 16.1 megapixel digital camera (NIKON WIDE 5XZoom. China) with, placed on a tripod $50 \mathrm{~cm}$ apart from the subject. The CVA is defined as the angle between a horizontal line passing through $\mathrm{C} 7$ and a line extending from the tragus of the ear to $\mathrm{C} 7$ was measured [15].

The spinous process of $\mathrm{C} 7$ and tragus were palpated. For easier palpation of $\mathrm{C} 7$ the participants were asked to perform flexion and extension of the head and marked with adhesive skin markers (fluorescent color adhesive squares of $1 \mathrm{~cm}$ diameter were used).

A picture of the lateral view of each participant was taken. A digital photo was taken and used to calculate the sagittal-C7-tragus angle. The craniovertebral angle was measured in degrees by using surgimap software program. According to Nemmers et al., [16] a young healthy adult is expected to exhibit an average normal head posture within a $10^{\circ}$ range from $49^{\circ}$ to $59^{\circ}$ of the C7-tragus angle. Therefore, subjects encountering angles less than $49^{\circ}$ were considered as forward head posture in this study.

\section{3- Visual analogue scale (VAS):}

Visual analogue scale (VAS) measures severity of patient's pain and its validation and reliability studies have been performed. VAS evaluates patient's pain perception on a scale of 10 vertical or 
horizontal lines from 0 (no pain) to 10 points (the most severe pain) [17].

The VAS was explained to the participants, that a 10 score is maximum pain that cannot be endured, and 0 score is no pain, and the subjects were asked to indicate the level of pain by placing a dash at the appropriate level on a $10 \mathrm{~cm}$ horizontal line. The subjects were provided with Arabic version of the VAS with "no pain" listed on the right side and "worst pain" on the left side.

\section{4- Tape measure:}

Tape was used to measure trunk range of motion (flexion, extension, side bending and rotation). The tape measuring method is a reliable method to assess active neck motions. Therapists can use a tape measure other than a goniometer to measure neck ROM. The intratester reliability coefficients, determined by correlation analysis, ranged from 0.80 to 0.95 for the experienced tester and 0.78 to 0.91 for the inexperienced tester [18].

Forward bending (Flexion): The patient Stood on the floor, heels together, knees straight, arms in neutral position, patient was asked to bend his trunk forward as far as he can, keep his knees straight. Measure the distance from Tip of right $3^{\text {rd }}$ finger to floor.

Backward bending (Extension): The patient Stood on the floor, heels together, arms in neutral position, patient was asked to bend his trunk backward as far as he can. Measure the distance from Spinous process of $\mathrm{C} 7$ to line joining right and left Posterior superior iliac spine (PSIS).

Side bending: The patient Stood on floor, heels together, knees straight, arms in neutral. The patient was asked to bend his trunk to the side (right and left) as far as he can, let his arm hang, keep fingers straight. Measure the distance from Tip of $3^{\text {rd }}$ finger to floor for the right and left side.

Rotation: Patient sat on plinth, knees together, hips flexed to $90^{\circ}$, arms folded across chest, patient was asked to sit up straight, turn to the right as far as he can. Measure the distance from Left posterior clavicular prominence to right greater trochanter. Repeat the procedure for the left side and measure the distance from the right posterior clavicular prominence to right greater trochanter.

Treatment procedures:

Study group $(A)$ :

The muscle energy technique (MET) was carried out for the study group involved the iliopsoas and lower back muscles where isometric contraction of the agonist muscle was performed for 10 seconds after that the patient was asked to relax for 2-3 seconds and then the examiner stretched the contracted muscle in the opposite direction for 10 seconds. This was repeated 3 times for each muscle. The duration of exercise session ranged from 5 to 10 minutes.

\section{A- Iliopsoas muscle:}

The patient was in supine lying position, the buttocks rested at the edge of the bed, the nontreated leg was held in a fully flexed position at hip and knee by the patient's hand and the treated leg was allowed to hang freely. The investigator stood front to the patient with one hand supporting the flexed limb or above iliac crest and the other hand was held the thigh of the affected leg at the knee joint to resist the patient to flex the hip. The patient started to isometrically contract the thigh toward hip flexion 10 seconds, followed by relaxation 3 seconds, and then the investigator took the thigh through the restricted range with slight painless pressure toward the floor on the anterior aspect of the thigh for 10 seconds. This exercise was repeated 3 times during the session $[\mathbf{1 9 , 2 0 ]}$.

\section{$B$ - Lower back muscles:}

The patient was in supine lying position and clasped his or her hands in front of both knees, while interlacing fingers together and the investigator assessed this position by his or her hand, then the patient pulled both knees towards the chest and stopped when pain was felt in the lower lumbar region. This is the restriction range. Shorter than this range, the patient pushed their knees against their hands for 10 seconds, followed by relaxation for 3 seconds and then he pulled both hands toward the chest to stretch the back muscle for 10 seconds, this was repeated for 3 times during the session [20,21].

Control group $(B)$ :

William's exercises performing order was as below [22]:

1- Sit up: In crook lying position, the patients pressed the lower back to the ground and then curled the head and shoulders up off the mat to the bottom tips of the shoulder blades for 5 counts. Then, they returned to the starting position. This exercise was repeated 5 times.

2- Pelvic tilt: In crook lying position, the patients pressed the lower back to the ground for 5 counts. Then, they relaxed. It was repeated 10 times. 
3- Trunk flexion: While the patients were in supine position, they brought both knees to the chest as much as they could and maintained this situation for 5 seconds then, they returned to the starting position. It was repeated 10 times.

4- Sit and reach: In long sitting position, the patients bent forward and stretched out their upper limbs toward the toes of each side, held the position for 5 seconds and then relaxed. It was repeated 10 times.

5- Hip flexor muscle stretch: The patients assumed the running starting position, leaned the trunk forward and put pressure on their back leg for 5 seconds. Then changed the legs, did the same movement for the other leg. It was repeated 5 times for each side.

6- Standing: Patients stood with the feet shoulder distance apart, tried to keep the trunk perpendicular to the ground as much as possible. While their eyes looked forward, slowly bent their knees and lowered the trunk. Then, they returned to the starting position. This exercise was repeated 10 times.

\section{Results}

\section{Subject characteristics:}

Table (1) showed the subject characteristics of both groups. There was no significant difference between both groups in the mean age, weight, height and BMI $(p<0.05)$. Also, there was no significant difference in sex distribution between groups $(p=0.88)$.

Effect of treatment on craniovertebral angle, lumbar lordosis angle, flexion and extension distance, right and left bending distance, right and left rotation distance and VAS.
Mixed MANOVA revealed that there was no significant interaction of treatment and time $(\mathrm{F}=$ $0.68, p=0.71)$. There was a significant main effect of time $(\mathrm{F}=184.54, p=0.001)$. There was no significant main effect of treatment $(\mathrm{F}=0.32, p=0.95)$. Table (2) showed descriptive statistics of measured variables as well as the significant level of comparison between groups and the significant level of comparison between pre and post treatment in each group.

\section{Within group comparison:}

There was a significant increase in craniovertebral angle and right and left rotation distance post treatment compared with that pre treatment in the group A and B ( $p>0.001)$. Also, there was a significant decrease in lumbar lordosis angle, flexion and extension distance, right and left bending distance and VAS post treatment compared with that pre treatment in the group A and B $(p>0.001)$ (Table 2).

\section{Between groups comparison:}

There was no significant difference in craniovertebral angle, lumber lordosis angle, flexion and extension distance, right and left bending distance, right and left rotation distance \& VAS between both groups pre and post treatment $(p>0.05)$ (Table 2$)$.

Table (1): Participant characteristics.

\begin{tabular}{|c|c|c|c|c|}
\hline & Study group & Control group & \multirow{2}{*}{$\begin{array}{c}t- \\
\text { value }\end{array}$} & \multirow{2}{*}{$\begin{array}{c}p- \\
\text { value }\end{array}$} \\
\hline & $\mathrm{X} \pm \mathrm{SD}$ & $\mathrm{X} \pm \mathrm{SD}$ & & \\
\hline Age (years) & $21.8 \pm 2$ & $22.2 \pm 1.85$ & -0.56 & 0.57 \\
\hline Weight (kg) & $66.8 \pm 6.91$ & $67.4 \pm 7.64$ & -0.22 & 0.82 \\
\hline Height $(\mathrm{cm})$ & $167.06 \pm 7.53$ & $169.46 \pm 9.3$ & -0.77 & 0.44 \\
\hline BMI (kg/m ) & $24.01 \pm 2.85$ & $23.57 \pm 3.12$ & 0.39 & 0.69 \\
\hline Males/females & s $7 / 8$ & $8 / 7$ & $\left(\chi^{2}=0.13\right)$ & 0.71 \\
\hline
\end{tabular}

Table (2): Mean craniovertebral angle, lumber lordosis angle, flexion and extension distance, right and left bending distance, right and left rotation distance and VAS pre and post treatment of the group A and B.

\begin{tabular}{|c|c|c|c|c|c|c|c|c|}
\hline & \multicolumn{2}{|c|}{ Pre treatment } & \multirow{3}{*}{$\begin{array}{c}p- \\
\text { value }\end{array}$} & \multicolumn{2}{|c|}{ Post treatment } & \multirow{3}{*}{$\begin{array}{c}p- \\
\text { value }\end{array}$} & \multicolumn{2}{|c|}{ Repeated measures } \\
\hline & Group A & Group B & & Group A & Group B & & Group A & Group B \\
\hline & $\mathrm{X} \pm \mathrm{SD}$ & $X \pm S D$ & & $\mathrm{X} \pm \mathrm{SD}$ & $\mathrm{X} \pm \mathrm{SD}$ & & $\begin{array}{c}p- \\
\text { value }\end{array}$ & $\begin{array}{c}p^{-} \\
\text {value }\end{array}$ \\
\hline Craniovertebral angle (degrees) & $49.27 \pm 4.74$ & $47.83 \pm 4.62$ & 0.4 & $52.36 \pm 5.37$ & $52.2 \pm 5$ & 0.93 & 0.001 & 0.001 \\
\hline Lumber lordosis angle (degrees) & $62.5 \pm 9.97$ & $60.93 \pm 7.53$ & 0.63 & $53.83 \pm 9.06$ & $51.23 \pm 5.43$ & 0.34 & 0.001 & 0.001 \\
\hline Flexion distance $(\mathrm{cm})$ & $12.93 \pm 4.35$ & $13.06 \pm 4.94$ & 0.93 & $2.2 \pm 0.77$ & $2.66 \pm 0.97$ & 0.15 & 0.001 & 0.001 \\
\hline Extension distance $(\mathrm{cm})$ & $37.93 \pm 3.47$ & $39.06 \pm 3.1$ & 0.35 & $34.53 \pm 3.46$ & $36 \pm 3.4$ & 0.25 & 0.001 & 0.001 \\
\hline Right bending distance $(\mathrm{cm})$ & $45.46 \pm 5.12$ & $46.2 \pm 3.94$ & 0.66 & $39.46 \pm 4.4$ & $40.46 \pm 3.9$ & 0.51 & 0.001 & 0.001 \\
\hline Left bending distance $(\mathrm{cm})$ & $45.8 \pm 4.45$ & $46 \pm 4.5$ & 0.9 & $40.06 \pm 4.36$ & $41.13 \pm 4.45$ & 0.51 & 0.001 & 0.001 \\
\hline Right rotation distance $(\mathrm{cm})$ & $78 \pm 6.14$ & $81.26 \pm 4.43$ & 0.1 & $82.13 \pm 6.3$ & $84.53 \pm 4.35$ & 0.23 & 0.001 & 0.001 \\
\hline Left rotation distance $(\mathrm{cm})$ & $78.26 \pm 5.62$ & $81.06 \pm 4.4$ & 0.14 & $82.66 \pm 6.46$ & $85.13 \pm 4.03$ & 0.22 & 0.001 & 0.001 \\
\hline VAS & $4.53 \pm 1.6$ & $4.86 \pm 1.55$ & 0.56 & $1.46 \pm 0.74$ & $1.4 \pm 0.63$ & 0.79 & 0.001 & 0.001 \\
\hline
\end{tabular}

$\mathrm{X}$ : Mean. SD: Standard deviation. $\quad p$-value: Level of significance. 


\section{Discussion}

This study was conducted to investigate the effect of lumbar hyperlordosis correction on craniovertebral angle in low back pain patients. Lumbar hyperlordosis correction was done by muscle energy technique and William exercises.

Regarding effect of lumbar hyperlodosis correction on pain level on VAS:

There is improvement in low back pain level on VAS, the reduction in pain due to MET can be explained on the basis of its neurophysiology, as described by Chaitow that post isometric relaxation (PIR) refers to the subsequent reduction in tone of the agonist muscle after isometric contraction. This occurs due to stretch receptors called Golgi tendon organ that are located in the tendon of the agonist muscle. These receptors react to overstretching of the muscle by inhibiting further muscle contraction. In more technical terms a strong muscle contraction against equal counterforce triggers the Golgi tendon organ. The afferent nerve impulse from the Golgi tendon organ enters the dorsal root of the spinal cord and meets with an inhibitory motor neuron [23].

Regarding effect of lumbar hyperlordosis correction on trunk ROM:

There is improvement in trunk ROM (flexion, extension, side bending and rotation), The effects of MET component for increase in ROM post intervention can be explained on the basis of physiological mechanisms behind the changes in muscle extensibility-reflex relaxation, viscoelastic change, and changes to stretch tolerance. Reflex muscle relaxation following contraction that has been proposed to occur by activation of the golgi tendon organs and their inhibitory influence on the amotor neuron pool. Combination of contractions and stretches (as used in MET) might be more effective for producing viscoelastic change than passive stretching alone, because the greater forces could produce increased viscoelastic change and passive extensibility [24].

Regarding effect of lumbar hyperlordosis correction on craniovertebral angle:

There is improvment in craniovertebral angle (CVA). This may be due to the fact that regaining a good lumbar posture will create a corresponding correctness within the rest of the spine as there is regional interdependence of spinal alignment, due to the double $\mathrm{S}$-shaped curve of the spine [25]. Changes in CVA may be due compensatory adjustments in upper and lower cervical spine that occur in order to maintain head orientation [26].
The findings of the current study are in agreement with Moon et al., [27] who stated that CVA while sitting with lumbar lordosis assistive support (LLAS) was significantly higher than that in the neutral sitting position. Neutral Sitting position produces posterior pelvic tilt which, in turn, reduces lumbar lordosis which affect cervical spine and decreases CVA. LLAS correct and regain natural lumbar lordosis which would have a positive impact on the neck posture. This mean that maintaining natural lumbar curvature is essential for ideal neck posture.

As well as the findings of the study are consistent with $\mathrm{Su}$ et al., [13] who measured abdominal muscle activities through surface EMG while maintaining the craniocervical posture in the craniocervical-extension (CCE), neutral, and craniocervicalflexion (CCF) postures in the hook-lying position. It was found that internal oblique, transversus abdominus and rectus abdominus had higher muscle activity in craniocervical flexion posture than in cranocervical extension posture and neutral posture while external oblique had higher muscle activity in craniocervical flexion than in craniocervical extension posture. So that, the facilitation of good craniocervical posture through CCF can affect lumbar alignment, thus increasing the abdominal muscle recruitment that is responsible for lumbar stabilization. This finding indicates that the joint or muscle state in one region of the human body can affect the muscles or joints of other regions of the body as well.

The findings of the present study are agree with Kuo et al., [28] who stated that the pelvis is considered to be the base for the spine, and its anteroposterior orientation affects the sagittal curves of the spine. The "neutral" position of the pelvis in standing has been defined as the posterior superior iliac spine (PSIS) and anterior superior iliac spine (ASIS) being approximately in the horizontal plane, a posture that produces the optimal degree of lumbar lordosis. Increased anterior pelvic tilt is said to result in a larger lumbar lordosis and compensatory increases in the thoracic and cervical curves above so that the head is maintained above the feet.

Regarding trunk ROM and pain intensity, our study is consistent with Jalal et al., [29] who demonstrated improvement in cervical ROM (flexion, extension, side bending and rotation) and improvement in pain intensity on VAS.

As well as, our study is in the same line with Mahajan et al., [30] who concluded that MET is effective in alleviating the mechanical neck pain 
in terms of decreasing pain intensity and increasing active cervical range of motion.

The findings of the current study are contradicted with Talati et al., [31] who stated that is no significant association between forward head posture assessed by CVA and alteration in spinal curvatures. This is may be due to the inability of the control factors that influence the craniocervical posture such as psychological situation, upper limb alignment, pelvic tilt, and lower limb alignment.

\section{Conclusion:}

The correction of lumbar hyperlrdosis had a positive effect on low back pain intensity, trunk range of motion and craniovertebral angle which affect head posture.

\section{References}

1- BRODY L.T. and HALL C.M.: Therapeutic Exercise: Moving Toward Function. $3^{\text {rd }}$ ed. Baltimore: Wolters Kluwer/Lippincott Williams \& Wilkins Health, p. 193, 2004.

2- MI-YEON S., WON-SUK C., SUNG-SOO K. and HYUNDAE S.: Correlation between Obesity and Lumbar Lordosis in Obese PreMenopausal Korean Females Korean Journal of Oriental Medicine, 25 (4): 43-50, 2004.

3- MIRBAGHERI S.S., RAHMANI R.A., FARMANI F., AMINI P. and NIKOO M.R.: Evaluating Kyphosis and Lordosis in Students by Using a Flexible Ruler and Their Relationship with Severity and Frequency of Thoracic and Lumbar Pain. Asian Spine Journal, 9 (3): 416-422, 2015.

4- LEE S.H., SON E.S., SEO E.M., SUK K.S. and KIM, K.T.: Factors determining cervical spine sagittal balance in asymptomatic adults: correlation with spinopelvic balance and thoracic inlet alignment. The Spine Journal, 15 (4): 705-712, 2015.

5- MAGEE D.J.: Orthopedic Physical Assessment. $6^{\text {th }}$ ed. St. Louis: Elsevier Health Sciences, p. 560, 2014.

6- NAKIPOGLU G.F., KARAGOZ A. and OZGIRGIN N.: The biomechanics of the lumbosacral region in acute and chronic low back pain patients. Pain Physician, 11(4): 505-511, 2008.

7- SARIKAYA S., ÖZDOLAP S., GÜMÜSTASS S. and KOÇ, Ü.: Low back pain and lumbar angles in Turkish coal miners. American Journal of Industrial Medicine, 50 (2): 92-96, 2007.

8- NA Y.M., KANG S.W., BAE H.S., KANG M.J., PARK J.S. and MOON J.H.: The analysis of spinal curvature in low back pain patients. J. Korean Acad Rehab Med., 20 (3): 669-674, 1996.

9- GLASSMAN S.D., BRIDWELL K., DIMAR J.R., HORTON W., BERVEN S. and SCHWAB F.: The impact of positive sagittal balance in adult spinal deformity. Spine, 30 (18): 2024-2029, 2005.

10- NORKIN C.C. and LEVANGLE P.: Joint Structure and Function: A comprehensive Analysis ( $\left.2^{\text {nd }} \mathrm{Ed}\right)$ Philadelphia: F.A. Davis Company, pp. 314-73, 1992.
11- JANDA V.: Muscle and cervicogenic pain syndromes. Physical therapy for the cervical and thoracic spine, 9, 1988.

12- LIEBENSON C. (Ed.).: Rehabilitation of the spine: A practitioner's manual. Lippincott Williams \& Wilkins, 2007.

13- SU J.G., WON S.J. and GAK H.: Effect of craniocervical posture on abdominal muscle activities. Journal of physical therapy science, 28 (2): 654-657, 2016.

14- HONG J.Y., SUH S.W., MODI H.N., HUR C.Y., SONG H.R. and PARK J.H.: Reliability analysis for radiographic measures of lumbar lordosis in adult scoliosis: A case control study comparing 6 methods. Eur. Spine J., 19 (9): 1551-7, 2010.

15- LEE E.S., KO C.W., SUH S.W., KUMAR S., KANG I.K. and YANG J.H.: The effect of age on sagittal plane profile of the lumbar spine according to standing, supine, and various sitting positions. Journal of Orthopaedic Surgery and Research, 9 (1): 11, 2014.

16- NEMMERS T.M., MILLER J.W. and HARTMAN M.D.: Variability of the forward head posture in healthy community-dwelling older women. Journal of Geriatric Physical Therapy, 32 (1): 10-14, 2009.

17- PRICE D.D., McGRATH P.A., RAFII A. and BUCKINGHAM B.: The validation of visual analogue scales as ratio scale measures for chronic and experimental pain. Pain, 17 (1): 45-56, 1983.

18- HSIEH C.Y. and YEUNG B.W.: Active neck motion measurements with a tape measure. Journal of Orthopaedic \& Sports Physical Therapy, 8 (2): 88-92, 1986.

19- CHAITOW L.: Muscle energy techniques. $2^{\text {nd }}$ edition. London: Edinburgh: Churchill Livingstone, 2001.

20- ABUTALEB E.E., ELDESOKY M.T. and EL RASOL S.A.: Effect of Muscle Energy Technique on Anterior Pelvic Tilt in Lumbar Spondylosis Patients. World Academy of Science, Engineering and Technology, International Journal of Medical, Health, Biomedical, Bioengineering and Pharmaceutical Engineering. Jul 4; 9 (8): 651-5, 2015.

21- CHAitOW L.: Muscle energy technique. $3^{\text {rd }}$ edition. London: Edinburgh: Churchill Livingstone, 2006.

22- LIEMOHN W.: Exercise prescription and the back. McGraw-Hill, 2001.

23- SHARMA D. and SEN S.: Effects of muscle energy technique on pain and disability in subjects with SI joint dysfunction. International Journal of Physiotherapy and Research, 2 (1): 305-311, 2014.

24- CHAITOW L. and CRENSHAW K.: Muscle energy techniques. Elsevier Health Sciences, 2006.

25- ANNETTS S., COALES P., COLVILLE R., MISTRY D., MOLES K., THOMAS B. and VAN DEURSEN R.: A pilot investigation into the effects of different office chairs on spinal angles. European Spine Journal, 21 (2): 165$170,2012$.

26- BLACK K.M., McCLURE, P. and POLANSKY M.: The influence of different sitting positions on cervical and lumbar posture. Spine, 21 (1): 65-70, 1996.

27- MOON J.H., JUNG J.H., HAHM S.C., OH H.K., JUNG K.S. and CHO H.Y.: Effects of lumbar lordosis assistive support on craniovertebral angle and mechanical properties 
of the upper trapezius muscle in subjects with forward head posture. Journal of Physical Therapy Science, 30 (3): 457-460, 2018.

28- KUO Y.L., TULLY E.A. and GALEA M.P.: Video analysis of sagittal spinal posture in healthy young and older adults. Journal of Manipulative and Physiological Therapeutics, 32 (3): 210-215, 2009.

29- JALAL Y., AHMAD A., RAHMAN A.U. and DAUD M.: Effectiveness of muscle energy technique on cervical range of motion and pain. JPMA. The Journal of the Pakistan Medical Association, 68 (5): 811-813, 2018.

30- MAHAJAN R., KATARIA C. and BANSAL K.: Comparative effectiveness of muscle energy technique and static stretching for treatment of subacute mechanical neck pain. Int. J. Health Rehabil Sci., 1 (1): 16-21, 2012.

31- TALATI D., VARADHRAJULU G. and MALWADE M.: The Effect of Forward Head Posture on Spinal Curvatures in Healthy Subjects. Asian Pacific Journal of Health Sciences, 2018.

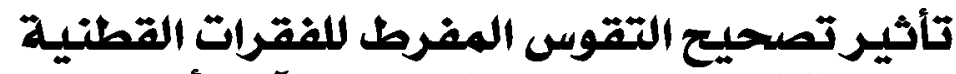 على زاوية القحفى الفقرى فى مرضى الهفى آلام أسفل الظهر الفير}

الخلفية: تعتبر المنطقة القطنية العجزية هى أهم منطقة في العمود الفقرى من حيث الحركة وتحمل الونن، حيث أن الاضطرابات الميكانيكية

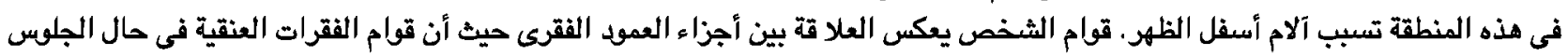

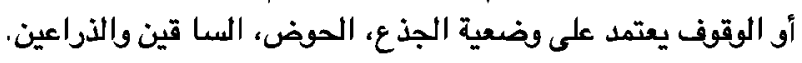

الثرض : التحقق من وجود تأثير لتصحيح التقوس المفرط للفقرات القطنية على ذاوية القحفى الفقرى وعلى مدى حركة الجذع، وعلى شدة

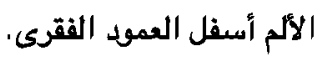

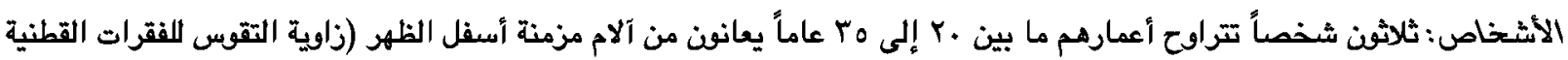

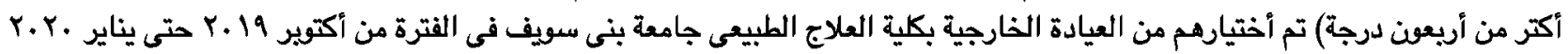

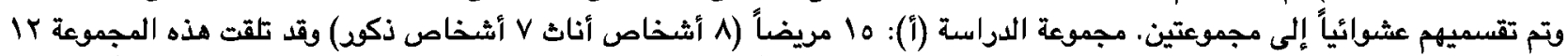

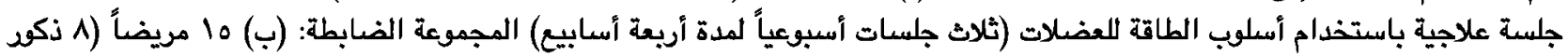

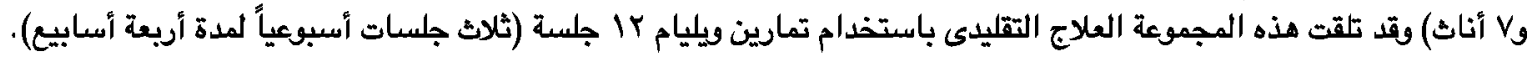
الأدوات: تم قياس ذاوية التقوس للفقرات القطنية وذاوية القدفى الفقرى ومدى شدة الالم ومدى حركة الجذع.

النتأج: يوجد تأثير إيجابى لتصحيح التقوس المفرط للفقرات القطنية على زاوية القحفى الفقرى وعلى مدى حركة الجذع ومدى شدة الآلم الكل من المجموعتين ولا يوجد فرق كبير بين الفيج المجموعات. 